\title{
EDUKASI PRENATAL ATTACHMENT DAPAT MENINGKATKAN KELEKATAN IBU DAN JANIN PADA IBU HAMIL RISIKO TINGGI
}

\section{[PRENATAL ATTACHMENT EDUCATION IMPROVES THE LEVEL OF PRENATAL ATTACHMENT IN HIGH RISK PREGNANT WOMEN]}

\author{
Mariani, Shinta Wahyusari, Nova Hikmawati \\ Stikes Hafshawaty Pesantren Zainul Hasan Genggong Pajarakan Probolinggo \\ Email: mariakenby@gmail.com
}

\section{ABSTRAK}

Latar Belakang: Prevalensi kehamilan risiko tinggi di Indonesia masih cukup tinggi yaitu sebesar $20 \%$. Ibu yang menderita penyakit dan komplikasi kehamilan dapat memengaruhi hasil dari kehamilan tersebut, yang berisiko terjadi morbiditas dan mortalitas ibu dan janin. Dampak psikologis kehamilan risiko tinggi yaitu kecemasan, stres, dan ibu mengalami krisis yang dapat memengaruhi hubungan antara ibu dengan janin. Kondisi tersebut dapat berlanjut pada hubungan ibu dan bayi setelah lahir. Oleh karena itu perlu adanya upaya untuk meningkatkan kelekatan ibu dan janin yang salah satunya dapat dilakukan dengan pemberian edukasi. Tujuan Penelitian : Penelitian ini bertujuan untuk mengetahui pengaruh edukasi prenatal attachment terhadap kelekatan ibu dan janin pada ibu hamil risiko tinggi di Kecamatan Paiton Kabupaten Probolinggo. Jenis penelitian Metode penelitian yang digunakan adalah quasy experiment dengan menggunakan pre-post test design. Populasi dalam penelitian ini adalah semua ibu hamil risiko tinggi di Kecamatan Dringu kabupaten Probolinggo. Teknik sampling yang digunakan pada penelitian ini adalah purpossive sampling yaitu dengan menentukan sampel sesuai dengan kriteria inklusi. Jumlah sampel yang akan digunakan adalah 20 responden. Teknik pengumpulan data menggunakan kuesioner. Data dianalisis menggunakan Wilcoxon dengan menggunakan SPSS. Hasil: Hasil yang didapatkan menunjukkan rerata skor kelekatan ibu dan janin sebelum dilakukan intervensi sebesar 52,15 dan sesudah intervensi sebesar 60,50. Terdapat perbedaan yang signifikan pada kelekatan ibu dan janin sebelum dan sesudah dilakukan intervensi dengan $p$ value sebesar $0,000(p<0,000)$. Edukasi prenatal attchment perlu dimasukkan ke dalam program kelas prenatal dan mulai diberikan kepada ibu hamil sejak trimester I. 
Kesimpulan : ada pengaruh edukasi prenatal attachment terhadap kelekatan ibu dan janin di wilayah kerja Puskesmas Paiton. Saran : edukasi prenatal attachment yang dimulai pada trimester I untuk memfasilitasi hubungan ibu dengan janin dan tercapainya kesejahteraan psikologis ibu hamil.

Kata Kunci: Edukasi prenatal attachment; Kelekatan ibu dan janin; Ibu hamil risiko tinggi.

ABSTRACT
Introduction: The prevalence of high-risk pregnancies in Indonesia is still quite high. Mothers who suffer from illness and pregnancy complications can influence the outcome of the pregnancy, which risks the occurrence of maternal and fetal morbidity and mortality. The psychological effects of high-risk pregnancies are anxiety, stress, and the mother experiences a crisis that can affect the relationship between mother and fetus. These conditions can continue in the relationship between mother and baby after birth. Therefore there needs to be an effort to increase the attachment of the mother and fetus, one of which can be done by providing education. Aims to determine the effect of prenatal attachment education on maternal and fetal attachment in high-risk pregnant women in Paiton Subdistrict, Probolinggo Regency. Methods: The study was conducted in Paiton Subdistrict, Probolinggo Regency in Mei-Juni 2019. The research method used was quasy experiment using pre-post test design. The population in this study were all high risk pregnant women in Dringu Subdistrict, Probolinggo Regency. The sampling technique used in this study was purposive sampling by determining the sample in accordance with the inclusion criteria. The number of samples to be used was 20 respondents. Data collection techniques using a questionnaire. Data were analyzed using Wilcoxon using SPSS. Results and Analysis: The results obtained showed the average score of attachment of the mother and fetus before the intervention was 52.15 and after the intervention was 60.50. There was a significant difference in the attachment of the mother and fetus before and after the intervention with a $p$ value of $0,000(p<0,000)$. Discussion: Prenatal care education needs to be included in the prenatal classroom program and started being given to pregnant women since the first trimester. Conclusion: there is an effect of prenatal attachment 
education on attachment of mother and fetus in the working area of Paiton Health Center. Suggestion: prenatal attachment education starting in the first trimester to facilitate the relationship between mother and fetus and to achieve psychological well-being of pregnant women.

Keywords: Attachment; Prenatal attachment; High risk pregnant women

Kehamilan merupakan salah satu proses fisiologis yang akan dialami oleh perempuan pada masa reproduksi. Akan tetapi, terdapat beberapa kondisi yang dapat menyebabkan kehamilan tersebut berubah menjadi patologis dan dapat mempengaruhi kesejahteraan ibu dan janin. Kondisi inilah yang disebut dengan kehamilan risiko tinggi (Jaideep., Prashant, \& Girija, 2017).

Prevalensi kehamilan risiko tinggi di dunia masih tergolong tinggi.

\section{PENDAHULUAN}

Samar, Dorgham, \& Suheir (2014) menyatakan bahwa terdapat 10-30\% ibu yang rutin menjalani perawatan antenatal didiagnosa mengalami kehamilan risiko tinggi dan dari jumlah tersebut, sebesar $70-80 \%$ mengalami kematian dan morbiditas perinatal. Menurut WHO, terdapat sekitar 800 perempuan hamil yang meninggal per hari dan sebesar 99\% dari jumlah tersebut terjadi di negara berkembang. Secara umum prevalensi kehamilan risiko tinggi sebesar $20 \%$ dan $50 \%$ mengalami kematian yang disebabkan oleh adanya komplikasi dalam kehamilan (Farajnezhad, Shaahmadi, Fashi, \& Daaylar, 2017).

Di Indonesia, komplikasi kehamilan yang sudah tertangani sebesar 73,31\% (Kemenkes, 2012). Di Jawa Timur, prevalensi tertinggi dari kehamilan risiko tinggi yaitu preeklampsi sebesar 30,90\% sedangkan yang paling rendah yaitu infeksi sebesar $4,87 \%$. Jumlah 
perkiraan ibu hamil risiko tinggi di Kabupaten Probolinggo tahun 2017 sebanyak 3.870 orang (20\% dari sasaran ibu hamil Jumlah perkiraan ibu hamil risiko tinggi di Kabupaten Probolinggo tahun 2017 sebanyak 3.870 orang ( $20 \%$ dari sasaran ibu hamil) 4.359 orang dideteksi risiko tinggi oleh masyarakat dan 6.849 dideteksi oleh tenaga kesehatan (Dinas Kesehatan Kabupaten Probolinggo, 2018).

Berdasarkan studi pendahuluan yang dilakukan pada tanggal 28 Pebruari 2019 di Wilayah Kabupaten Probolinggo, jumlah kehamilan risiko tinggi yaitu sebesar $24 \%$ dari seluruh kehamilan pada tahun 2018. Hasil wawancara pada $10 \mathrm{ibu}$ hamil didapatkan bahwa semua ibu hamil tidak tahu tentang kelekatan ibu dan janin dan cara meningkatkan kelekatan selama kehamilan.

Kehamilan meskipun dalam kondisi normal merupakan kondisi yang dapat mempengaruhi kondisi psikologis seorang perempuan diantaranya adalah stres, kecemasan dan depresi. Jika kondisi kehamilan disertai dengan komplikasi, maka hal ini dapat meningkatkan tingkat stres dan kecemasan pada ibu hamil karena adanya ketakutan dan kekhawatiran terkait keberlangsungan proses kehamilan dan kondisi janin (Farajnezhad, Shaahmadi, Fashi, \& Daaylar, 2017).

Ibu hamil risiko tinggi menunjukkan tingkat depresi yang lebih tinggi yaitu sebesar 18\% hingga 58\% (Gourounti, Karpatiothaki, \& Vaslamatzis, 2015). Hal ini dapat mempengaruhi kondisi psikologis yang akhirnya dapat memberikan dampak negatif pada pemenuhan tugas perkembangan selama kehamilan salah satunyayaitu memulai 
ikatan ibu dengan janin. (Gourounti, Karpatiothaki, \& Vaslamatzis, 2015).

Kelekatan ibu dan janin mengacu pada ikatan emosional antara ibu dan janin dan merupakan indikator kesejahteraan dan efisiensi ibu pada periode postnatal (Akbarzadeh, Dokuhaki, Joker, Pishva \& Zare, 2016). Robinson (2010) dalam (Akbarzadeh, Dokuhaki, Joker, Pishva \& Zare, 2016) menyebutkan bahwa kelekatan tidak dimulai setelah kelahiran bayi, akan tetapi berkembang dalam tujuh tahap yaitu saat perencanaan kehamilan, adaptasi dengan kehamilan, menerima kehamilan, merasakan gerakan janin, mengenali janin sebagai individu, melahirkan, dan melihat dan menyentuh bayi.

Kondisi kehamilan risiko tinggi dapat mempengaruhi kelekatan ibu dan janin. Hal ini disebabkan ibu hamil risiko tinggi dapat mengalami kesulitan dalam membina hubungan dengan janin karena adanya perasaan takut kehamilan tidak dapat dipertahankan atau terjadi anomali pada janin (Rifkin, 2007). Selain itu, ibu hamil risiko tinggi juga dapat mengalami kecemasan. Cevirme, Ilcioglu, \& Hamlaci (2017) melakukan penelitian terhadap 502 ibu hamil dan hasil penelitian tersebut didapatkan bahwa kecemasan selama kehamilan memiliki pengaruh negatif terhadap kelekatan ibu dan janin.

Kelekatan yang kuat antara ibu dan janin dapat berpengaruh terhadap perkembangan fisik janin selama kehamilan dan setelah lahir. Selain itu, kelekatan juga dapat berpengaruh terhadap adaptasi ibu selama kehamilan (Akbarzadeh, Dokuhaki, Joker, Pishva \& Zare, 2016). Franc et al (2009), hubungan ini terbentuk selama kehamilan dan 
sangat penting untuk perkembangan psikologis bayi. Lee et al menemukan bahwa mengajarkan perilaku kognitif berbasis kelekatan pada ibu secara langsung memengaruhi kualitas interaksi ibu dan janin serta kesehatan mental bayi setelah lahir. Demikian pula, penelitian oleh Koniak et al mengungkapkan bahwa kelekatan yang meningkat menghasilkan kedekatan dan emosi yang menyenangkan yang berkontribusi terhadap kesehatan mental ibu dan bayi.

Salah satu metode yang dapat digunakan untuk meningkatkan kelekatan ibu dan janin adalah dengan memberikan pendidikan kesehatan kepada ibu hamil. Dengan adanya pendidikan kesehatan diharapkan dapat meningkatkan pengetahuan dan keterampilan ibu hamil. Selain itu, dengan memberikan pendidikan kesehatan dapat memotivasi ibu untuk terlibat dalam berbagai kegiatan yang dilakukan. Tujuan penelitian ini yaitu untuk mengetahui pengaruh edukasi prenatal attachment terhadap kelekatan ibu dan janin pada ibu hamil risiko tinggi. Selama ini, penelitian difokuskan pada pengaruh faktor emosional terhadap kelekatan ibu dan janin, sehingga peneliti tertarik untuk meneliti lebih lanjut tentang pengaruh pendidikan kesehatan terhadap kelekatan ibu dan janin

\section{METODE PENELITIAN}

Penelitian ini menggunakan desain penelitian quasy experiment menggunakan pre-post test group design. Populasi dalam penelitian ini adalah semua ibu hamil risiko tinggi di wilayah kerja Puskesmas Paiton Kabupaten Probolinggo berjumlah 55 orang. Teknik sampling yang digunakan yaitu purpossive sampling dan didapatkan jumlah sampel sebesar 20 responden. 
Variabel yang diukur dalam penelitian ini terdiri dari variabel independen yaitu edukasi prenatal attachment. Variabel dependen pada penelitian ini yaitu kelekatan ibu dan janin pada ibu hamil risiko tinggi.

Data dikumpulkan menggunakan kuesioner untuk mengukur Penelitian ini menggunakan kuesioner prenatal attachment inventory (PAI) untuk mengukur PA. Kuesioner ini pertama kali dibuat oleh Muller (1993) yang telah diterjemahkan ke dalam bahasa Indonesia dan diuji validitas dengan nilai 0,733 dan reliabilitas dengan nilai 0,924.

Setelah data terkumpul, dilakukan uji statistik menggunakan Wilcoxon untuk mengetahui adanya pengaruh edukasi prenatal attachment terhadap kelekatan ibu dan janin pada ibu hamil risiko tinggi sebelum dan sesudah dilakukan intervensi. Uji Wilcoxon dilakukan karena kedua data merupakan distribusi data yang tidak normal. Analisa data secara statistik dilakukan dengan menggunakan bantuan komputer SPSS dengan tingkat kemaknaan $p \leq 0,05$.

Ethical Consideration : Penelitian ini sudah dilakukan uji etik di STIKES Hafshawaty Pesantren Zainul Hasan Probolinggo dengan No sertifikat KEPK/177/STIKES-PZH/VI/2019

\section{HASIL DAN}

PEMBAHASAN

\section{a. Karakteristik Responden}

Tabel 1. Karakteristik Responden berdasarkan usia dan usia kehamilan $(n=55)$

\begin{tabular}{ccccc}
\hline Variabel & Mean & SD & Min-Max & $95 \% \mathrm{Cl}$ \\
\hline Usia & 27.60 & 4.441 & $20-34$ & $25.52-29.68$ \\
\hline Usia kehamilan & 26.85 & 10.525 & $8-39$ & $21.92-31.78$ \\
\hline
\end{tabular}


Tabel 2. Karakteristik Responden berdasarkan tingkat pendidikan dan

\begin{tabular}{llc}
\multicolumn{2}{c}{ gravida $(\mathrm{n}=55)$} & \multicolumn{2}{c}{ Frekuensi } \\
\cline { 2 - 3 } \multicolumn{2}{c}{ Variabel Demografi } & \multicolumn{2}{c}{ No. } \\
\hline Tingkat Pendidikan : & 5 & 25 \\
Pendidikan Dasar & 4 & 20 \\
Pendidikan Menengah & 11 & 55 \\
Pendidikan Tinggi & & \\
\hline Gravida & 7 & 35 \\
Primigravida & 13 & 65 \\
Multigravida & \multicolumn{2}{c}{} \\
\hline
\end{tabular}

Rata-rata usia responden yang digunakan dalam penelitian ini adalah 27,60 tahun, dengan rata-rata usia kehamilan 26,85 yang dijelaskan pada tabel 1. Dari 20 responden, sebanyak 11 (55\%) berpendidikan tinggi, 13 (65\%) merupakan multigravida.

\section{b. Kelekatan Ibu dan Janin Sebelum Dilakukan Edukasi Prenatal}

\section{Attachment}

Tabel 3. Kelekatan Ibu dan Janin sebelum dilakukan edukasi prenatal attachment

\begin{tabular}{ccccc}
\hline Variabel & Mean & SD & Min-Max & 95\% Cl \\
\hline Kelekatan Ibu dan Janin & 52.15 & 12.330 & $40-82$ & $46.38-57.92$ \\
\hline
\end{tabular}

Hasil analisis didapatkan rerata skor kelekatan ibu dan janin sebelum dilakukan edukasi prenatal attachment adalah 52,15 (95\% Cl: 46,38 - 57,92), dengan standar deviasi 12,330 minggu. Skor terendah adalah 40 dan skor tertinggi 82. Dari hasil estimasi interval dapat disimpulkan bahwa 95\% diyakini bahwa rerata skor kelekatan ibu dan 
Volume 08 No.01, Iuli 2020

e-ISSN : 26559382

p-ISSN : 22524843

janin sebelum dilakukan edukasi prenatal attachment adalah di antara $46,38-57,92$.

\section{c. Kelekatan Ibu dan Janin Setelah Dilakukan Edukasi Prenatal}

\section{Attachment}

Tabel 4. Kelekatan Ibu dan Janin sebelum dilakukan edukasi prenatal attachment

\begin{tabular}{ccccc}
\hline Variabel & Mean & SD & Min-Max & $95 \% \mathrm{Cl}$ \\
\hline Kelekatan Ibu dan Janin & 60.50 & 10.870 & $39-82$ & $55.41-65.49$ \\
\hline
\end{tabular}

Hasil analisis didapatkan rerata skor kelekatan ibu dan janin setelah dilakukan edukasi prenatal attachment adalah 60,50 (95\% Cl: $55,41-65,49)$, dengan standar deviasi 10,870 . Skor terendah adalah 39 dan skor tertinggi 82. Dari hasil estimasi interval dapat disimpulkan bahwa 95\% diyakini bahwa rerata skor kelekatan ibu dan janin sebelum dilakukan edukasi prenatal attachment adalah di antara 55,41 $-65,49$.

\section{d. Hasil Analisis Pengaruh Edukasi Prenatal Attachment terhadap} Kelekatan Ibu dan janin pada Ibu Hamil Risiko Tinggi

Tabel 5. Analisis Hasil Uji Wilcoxon Kelekatan Ibu dan Janin pada Ibu Hamil Risiko Tinggi

\begin{tabular}{cccccc}
\hline $\begin{array}{c}\text { Kelekatan Ibu } \\
\text { dan Janin }\end{array}$ & $\mathrm{n}$ & Median (Min-Max) & SD & $95 \% \mathrm{Cl}$ & $\mathrm{P}$ \\
\hline Pretest & 20 & $47.50(40-82)$ & 12.330 & $46.38-57.92$ & 0.000 \\
Posttest & 20 & $60,50(39-82)$ & 10,870 & $55.41-65.59$ & \\
\hline
\end{tabular}


Pada tabel di atas disajikan data variabel kelekatan ibu dan janin pada ibu hamil risiko tinggi sebelum dan sesudah diberikan intervensi edukasi prenatal attachment. Dari tabel di atas didapatkan hasil bahwa terdapat perbedaan yang signifikan kelekatan ibu dan janin sebelum dan setelah diberikan intervensi dengan nilai $\rho$ value $0,000(\rho<0,05)$

Berdasarkan hasil penelitian, didapatkan bahwa rata-rata skor kelekatan ibu dan janin pada ibu hamil risiko tinggi sebesar 46,38. Alat ukur yang digunakan dalam penelitian ini adalah Prenatal Attachment Inventory yang pertama kali dibuat oleh Muller (1993). Kuesioner ini memiliki skor terendah 21 dan skor tertinggi sebesar 84. Hasil analisis dalam penelitian ini menunjukkan bahwa rerata skor kelekatan ibu dan janin pada ibu hamil risiko tinggi sebelum dilakukan intervensi tergolong rendah.

Proses kelekatan dimulai saat ibu mulai menerima keberadaan janin dalam kandungan dan merasakan gerakan janin (Khan, 2011). Pada saat ini ibu akan berusaha memenuhi kebutuhan janin dan mulai fokus pada kesejahteraan janin (Ossa, Bustos, \& Fernandez, 2012; \& Mehran, Simbar, Shams, Ramezani-Tehrani, \& Nasiri, 2012). Ibu mulai berusaha untuk tahu, selalu bersama, menghindari kehilangan, melindungi dan memenuhi kebutuhan janin (Condon, 1993). Proses ini berubah-ubah selama kehamilan. Hal ini dipengaruhi oleh adanya perubahan biologi dan fisiologi ibu dan janin, respon fisiologis, dan lingkungan sosial selama kehamilan. Ketidaknyamanan selama 
kehamilan seperti morning sickness, dapat membuat ibu merasa kehamilan semakin nyata, menumbuhkan rasa kebahagiaan dan ibu dapat merasa gugup (National Abandon Infants Assisstance Resource Center, 2013).

Beberapa penelitian menunjukkan bahwa salah faktor yang dapat mempengaruhi kelekatan ibu dan janin adalah adanya kondisi risiko tinggi atau penyulit selama kehamilan (Kemp, 1987). Perkembangan kondisi risiko tinggi dapat menghambat pemenuhan tugas maternal selama kehamilan (Rifkin, 2007). Beberapa tugas maternal selama kehamilan yaitu memastikan keamanan kehamilan dan persalinan, penerimaan terhadap kehamilan oleh diri sendiri dan orang lain, mencari kepastian dan penerimaan diri sebagai ibu (binding-in), dan giving of her self (Rubin, 1984 dalam Brandon, Pitts, Denton, Stringer, \& Evans, 2009). Ibu hamil risiko tinggi dapat menunjukkan sikap menolak kehadiran janin selama masa kehamilan karena takut kehamilan tidak dapat dipertahankan (Kemp \& Page 1987).

Berdasarkan hasil penelitian, didapatkan bahwa rata-rata skor kelekatan ibu dan janin pada ibu hamil risiko tinggi setelah dilakukan edukasi prenatal attachment sebesar 60,50. Hal tersebut menunjukkan bahwa terdapat peningkatan yang signifikan pada skor kelekatan ibu dan janin setelah dilakukan edukasi prenatal attachment. Edukasi yang dilakukan dalam penelitian ini terdiri dari 3 pertemuan yaitu pertemuan pertama untuk membahas tentang konsep prenatal attachment, pertemuan kedua dan ketiga yaitu melatih ibu untuk 
merasakan keberadaan janin dan mengurangi stres selama kehamilan.

Edukasi selama prenatal dapat meningkatkan kesejahteraan psikologis ibu hamil. Secara teori menunjukkan bahwa ibu hamil risiko tinggi dapat mengalami tingkat kecemasan yang lebih tinggi daripada ibu hamil normal. Hal ini disebabkan oleh adanya perasaan ambigu dan kekhawatiran ibu terhadap kelangsungan kehidupan janin. Edukasi prenatal dapat memfasilitasi ibu dalam membentuk hubungan dengan janin dan memenuhi kebutuhan psikologis ibu. Hal ini didasarkan pada pendidikan kesehatan dapat mendukung ikatan ibu dengan janin melalui serangkaian materi yang dapat membentuk kesadaran ibu terhadap perkembangan janin dan respon janin terhadap stimulus yang diberikan oleh orang tua (Bellieni, Ceccarelli, Rossi, Buonocore, Maffei, Perrone \& Petraglia, 2007).

Salah satu intervensi edukasi prenatal attachment yang diberikan pada penelitian ini salah satunya adalah melatih ibu untuk merasakan keberadaan janin dengan cara menghitung pergerakan janin. Hal ini didasarkan pada mulai munculnya kelekatan antara ibu dan janin pada waktu janin semakin besar khususnya pada saat quickening. Ibu hamil yang dapat merasakan aktivitas janin menunjukkan kelekatan yang lebih tinggi (Sastaad, 2011).

Penelitian yang dilakukan oleh Guney (2019) menunjukkan bahwa ibu hamil yang diajarkan untuk menghitung pergerakan janin memiliki skor kelekatan yang lebih tinggi pada dimensi kualitas kelekatan menggunakan instrumen Maternal antenatal attachment scale (MAAS). Dimensi tersebut mewakili kualitas pengalaman 
emosional yang dirasakan oleh ibu hamil terhadap janin. Ibu hamil yang menyentuh perutnya sambil menghitung pergerakan janin dapat meningkatkan sensitivitas dan kepekaan ibu terhadap janin sehingga tercipta hubungan yang kuat dengan janin.

Selain menghitung pergerakan janin, intervensi yang diberikan adalah dengan mengajarkan ibu untuk mengetahui posisi janin dalam uterus menggunakan manuver leopold. Metode ini diharapkan dapat meningkatkan kemampuan ibu hail untuk menentukan posisi janin dan menstimulasi kesadaran ibu terhadap keberadaan janin. Nishikawa \& Sakakibara (2013) melakukan penelitian tentang penggunaan manuver leopold untuk meningkatkan skor PAl. Hasil penelitian tersebut menunjukkan bahwa intervensi menggunakan manuver leopold dapat meningkatkan hubungan antara ibu dan janin. Hal ini menunjukkan bahwa kesadaran ibu tentang posisi janin dan bagian tubuh janin dapat meningkatkan kelekatan ibu dan janin selama kehamilan. Intervensi keperawatan menggunakan manuver leopold perlu dimasukkan ke dalam program edukasi ibu hamil untuk meningkatkan kelekatan ibu dan janin yang nantinya dapat berdampak pada peningkatan kesejahteraan psikologis ibu.

Data hasil analisis uji Wilcoxon didapatkan bahwa ada perbedaan pengaruh edukasi prenatal attchment terhadap kelekatan ibu dan janin pada ibu hamil risiko tinggi sebelum dan sesudah dilakukan intervensi dengan nilai signifikan sebesar 0,000 $(p<0,05)$.

Hal ini sejalan dengan hasil penelitian yang dilakukan oleh Abasi, Tafazzoli, Esmaily, \& Hasanabadi (2013) yang menunjukkan 
bahwa terdapat perbedaan skor kelekatan ibu dan janin sebelum dan sesudah dilakukan intervensi. Intervensi yang dilakukan pada penelitian tersebut yaitu edukasi untuk melatih ibu hamil merasakan bayi dengan menghitung pergerakan janin selama satu bulan.

Beberapa penelitian tentang edukasi selama prenatal terhadap kelekatan ibu dan janin menunjukkan hasil yang berbeda-beda. Penelitian sebelumnya yang dilakukan oleh Bellieni, Ceccarelli, Rossi, Buonocore, Maffei, Perrone \& Petraglia (2007) kepada 77 ibu hamil menggunakan intervensi edukasi prenatal selama trimester satu dan dua menunjukkan bahwa pada kelompok ibu hamil yang dilakukan intervensi memiliki skor PAI yang lebih tinggi daripada kelompok kontrol.

Penelitian lain yang dilakukan oleh Baghdari, Sahebzad, Kheirkhah, \& Azmoude (2016) tentang edukasi prenatal menggunakan metode pelatihan adaptasi selama kehamilan menunjukkan bahwa di akhir program, terdapat perbedaan skor kelekatan ibu dan janin yang signifikan antara kelompok intervensi dengan kelompok kontrol. Hal ini menunjukkan bahwa edukasi yang dilakukan dapat meningkatkan interaksi antara ibu dan janin.

Berdasarkan hasil penelitian yang dilaksanakan, maka dapat disimpulkan bahwa ada pengaruh edukasi prenatal attachment terhadap kelekatan ibu dan janin di wilayah kerja Puskesmas Paiton.

Berdasarkan hasil penelitian dan pembahasan sebelumnya, maka saran yang dapat diajukan adalah perlu adanya Perlunya edukasi prenatal attachment yang dimulai pada trimester I untuk memfasilitasi 
hubungan ibu dengan janin dan tercapainya kesejahteraan psikologis ibu hamil. Proses edukasi ini membutuhkan modul sebagai media pembelajaran dan dapat dimasukkan ke dalam program rutin selama kelas prenatal dilaksanakan. Perlunya penambahan materi tentang prenatal attachment pada mata ajar keperawatan maternitas untuk mendukung pemahaman mahasiswa tentang adaptasi psikologis selama kehamilan. Penelitian ini menggunakan ibu hamil risiko tinggi sebagai responden penelitian, sehingga perlu penelitian lebih lanjut tentang edukasi prenatal attachment menggunakan berbagai metode untuk memudahkan responden dalam memahami konsep dan mempraktikkan cara meningkatkan kelekatan ibu dan janin. Selain itu, perlu menggunakan sampel lebih luas dengan responden yang digunakan adalah seluruh ibu hamil yang normal dan risiko tinggi, sehingga bisa membandingkan kelekatan yang terbentuk antara ibu hamil normal dan risiko tinggi setelah diberikan edukasi.

\section{DAFTAR PUSTAKA}

Abasi, E., Tafazzoli, M., Esmaily, H. and Hasanabadi, H., (2013). The effect of maternal-fetal attachment education on maternal mental health. Turkish Journal of Medical Sciences, 43(5), pp.815-820.

Akbarzadeh, M., Dokuhaki, A., Joker, A., Pishva, N., \& Zare, N. (2016). Teaching attachment behaviors to pregnant women: a randomized controlled trial of effects on infant mental health from birth to the age of three months. Ann Saudi Med, 36(3), 175-183.

Baghdari, N., Sahebzad, E. S., Kheirkhah, M., \& Azmoude, E. (2016). The effects of pregnancy-adaptation training on maternal-fetal attachment and adaptation in pregnant women with a history of baby loss. Nursing and midwifery studies, 5(2). e28949 
Bellieni, C.V., Ceccarelli, D., Rossi, F., Buonocore, G., Maffei, M., Perrone, S. and Petraglia, F., (2007). Is prenatal bonding enhanced by prenatal education courses?.Minerva ginecologica, 59(2), pp.125-130.

Brandon, A. R., Trivedi, M. H., Hynan, A. S., Miltenberger, P., Labat, D., Rifkin, J., \& Stringer, C. A. (2009). Prenatal depression in women hospitalized for obstetric risk. J Clin Psychiatry, 69(4), 635-643.

Çevirme, A., Özdemir, Ilcioglu, K., \& Hamlaci, Y. (2017). Anxiety and prenatal attachment levels in pregnancy and influencing factors. New Trends and Issues Proceedings on Humanities and Social Sciences. [Online], 4 (2), 11-20

Condon, J.T. (1993). The assessment of antenatal emotional attachment: developments of a questionnaire instrument. British Journal of Medical Psychology, 66, 167-183. doi: 10.1111/j.2044-8341.1993.tb01739.x.

Dinas Kesehatan Kabupaten Probolinggo. (2017). Profil Kesehatan Kabupaten Probolinggo 2017. Diakses tanggal 22 Desember 2018

Farajnezhad, F., Shaahmadi, F., Fashi, Z., \& Daaylar, L. (2017). Prevalence of High Risk Pregnancy and Some Relevant Factors in Referred Women to Health Centers. Journal of Scientific Achievements, 2(12): 4-7.

Franc N, Maury M, Purper-Ouakil D. 2009). [ADHD and attachment processes: are they related?]. Encephale, 35 (3), 256-261.

Gourounti, C., Karpathiotaki, N., \& Vaslamatzis, G. (2015). Psychosocial stress in high risk pregnancy. International Archives of Medicine, 8(95), 1-9.

Güney, E. and Uçar, T., 2019. Effect of the fetal movement count on maternal-fetal attachment.Japan Journal of Nursing 
Science, 16(1), pp.71-79.

Jaideep K. C., Prashant D., \& Girija A. (2017). Prevalence of high risk among pregnant women attending antenatal clinic in rural field practice area of Jawaharlal Nehru Medical College, Belgavi, Karnataka, India. International Journal of Community Medicine and Public Health, 4 (4), 1257-1259.

Kemp, V. H \& Page, C. K. (1987). Maternal prenatal attachment in normal and high-risk pregnancies. Journal of Obstetric, Gynecologic, \& Neonatal Nursing, 16 (3), 179-184. doi: 10.1111/j.1552-6909.1987.tb01455.x.

Khan, S. (2011). Baby steps: A bonding program for adolescent mothers and their infants. Dissertation.

Kementerian Kesehatan Republik Indonesia. (2012). Profil Kesehatan Indonesia (2012). Jakarta.

Kemp, V. H \& Page, C. K. (1987). Maternal prenatal attachment in normal and high-risk pregnancies. Journal of Obstetric, Gynecologic, \& Neonatal Nursing, 16 (3), 179-184. doi: 10.1111/j.1552-6909.1987.tb01455.x.

Mehran, P., Simbar, M., Shams, J., Ramezani-Tehrani, F., \& Nasiri, N. (2013). History of perinatal loss and maternal-fetal attachment behaviors. Women and Birth, 26, 185-189. doi: 10.1016/j.wombi.2013.04.005.

Muller, ME. (1993). Development of the Prenatal Attachment Inventory. West J Ners Res, 15 (2), 199-211.

National Abandon Infants Assistance Resource Center. (2013). Promoting maternal-fetal attachment with women affected by hiv and/or substance use. Retrieved from aia.berkeley.edu/media/pdf/fetalattachment.pdf.

Nishikawa, M., \& Sakakibara, H. (2013). Effect of nursing intervention 
program using abdominal palpation of Leopold's maneuvers on maternal-fetal attachment. Reproductive Health, 10(1), 10-12.

Ossa, X., Bustos, L., \& Fernandez, L. (2012). Prenatal attachment and associated factors during the third trimester of pregnancy in Temuco, Chile. Midwifery, 28, e689-e696. doi: 10.1016/j.midw.2011.08.015.

Rifkin, J. B. (2007). Prenatal attachment during antepartum hospitalization: Associations with pregnancy planning, partner relationship, and postpartum depression and anxiety. Desertation. https://repositories.tdl.org/utswmed$\mathrm{ir} /$ bitstream/handle/2152.5/535/rifkinjamie.pdf?sequence=3.

Saastad, E., Israel, P., Ahlborg, T., Gunnes, N. and Frøen, J.F., 2011. Fetal Movement Counting-Effects on Maternal-Fetal Attachment: A Multicenter Randomized Controlled Trial. Birth, 38(4), pp.282-293. 